\title{
Qualidade da silagem de aveia preta sob efeito de estádios fenológicos, tamanhos de partícula e pré-murchamento
}

\author{
Black oat silage quality under ensiling phenological stages, particle size and pre- \\ wilting
}

\section{PARIS, Wagner ${ }^{1 *}$; ZAMARCHI, Gustavo ${ }^{2}$; PAVINATO, Paulo Sérgio ${ }^{3}$; MARTIN, Thomas Newton ${ }^{4}$}

\footnotetext{
${ }^{1}$ Universidade Tecnológica Federal do Paraná, Programa de Pós-Graduação em Zootecnia, Dois Vizinhos, Paraná, Brasil.

${ }^{2}$ Universidade Tecnológica Federal do Paraná, Dois Vizinhos, Paraná, Brasil.

${ }^{3}$ Universidade de São Paulo, Escola superior de agricultura Luiz de Queiroz, Departamento de Solos, Piracicaba, São Paulo, Brasil.

${ }^{4}$ Universidade Federal de Santa Maria, Departamento de Agronomia, Santa Maria, Rio Grande do Sul, Brasil.

*Endereço para correspondência: wagparis@yahoo.com.br
}

\section{RESUMO}

Objetivou-se com esta pesquisa avaliar os efeitos do estádio fenológico, o tamanho de partícula e o pré-murchamento sobre as características de fermentação e valor nutritivo da silagem de aveia preta (Avena strigosa). $\mathrm{O}$ experimento foi conduzido durante o período hibernal de 2011, em "latossolo vermelho" de textura argilosa localizado em Renascença, sudoeste do Paraná, Brasil. O delineamento experimental foi inteiramente casualizado em esquema trifatorial $(3 \times 2 \times 2)$ com quatro repetições, sendo os fatores tamanhos médios de partícula: 5 ; 13 e $22 \mathrm{~mm}$; estádios de ensilagem: início do florescimento e florescimento pleno; e manejos: com e sem pré-murchamento. $\mathrm{O}$ tamanho de partícula alterou apenas o $\mathrm{pH}$ do material ensilado, com melhores resultados com $22 \mathrm{~mm}$, sem efeitos na composição bromatológica da silagem produzida. A operação de pré-murchamento é eficiente em restringir a emissão de efluentes no início do florescimento e, também, confere à silagem melhores condições de fermentação, com redução da capacidade tampão de 87,68 para 53,20 meq $\mathrm{NaOH} 100 \mathrm{~g} \mathrm{MS}^{-1}$ e do $\mathrm{pH}$ de 3,64 para 3,15 , os quais garantem melhor preservação do valor nutritivo da forragem, possuindo menores teores de fibra em detergente neutro (FDN) e fibra em detergente acido (FDA), com maior proteína bruta (PB), digestibilidade in vitro da matéria seca (DIVMS) e nutrientes digestíveis totais (NDT).
Com o avanço da maturidade, verifica-se elevação nos teores de FDN e FDA e redução nos teores de PB, DIVMS e NDT. A ensilagem em início de florescimento, seguida de prémurchamento, possui condições adequadas para fermentação e apresenta melhor valor nutritivo.

Palavras-chave: Avena strigosa Scherb, capacidade tampão, digestibilidade in vitro da matéria seca, emissão de efluente, $\mathrm{pH}$ da silagem

\section{SUMMARY}

The objective was evaluate the effect of growth stage, particle size and pre-wilting on fermentation characteristics and nutritional value of the black oat silage (Avena strigosa $\mathrm{S}$.). The experiment was conducted during the winter of 2011, in the city of Renascença, Southwest region of Paraná State, Brazil. The experimental design was completely randomized distributed in a factorial $(3 \times 2 \times 2)$ with four replications. The factors evaluated were particle sizes: 5,13 and $22 \mathrm{~mm}$; ensilage stages: early flowering and full flowering; and management: with and without pre-wilting. The particle size changes only the silage $\mathrm{pH}$, with better results under $22 \mathrm{~mm}$, without any effects on the chemical composition of the silage produced. The management of pre-wilting is efficient to restrict effluents emission at early flowering, also gives better silage fermentation 
conditions, with reduced buffering capacity of 87.68 to $53.20 \mathrm{meq} 100 \mathrm{~g} \mathrm{NaOH} \mathrm{DM}{ }^{-1}$ and of $\mathrm{pH}$ from 3.64 to 3.15 , which ensure a better preservation of the forage nutritional value, having lower levels of neutral detergent fiber (NDF) and acid detergent fiber (ADF) with greater crude protein (CP), in vitro dry matter digestibility (IVDMD) and total digestible nutrients (TDN). With the advancement of maturity it is observed increases in NDF and $\mathrm{ADF}$ and decreases in the values of $\mathrm{CP}$, IVDMD and TDN. The ensilage in the early flowering stage followed by pre-wilting has suitable conditions for fermentation and has better nutritional value.

Keywords: Avena strigosa Scherb, buffer capacity, in vitro digestibility of dry matter, effluent emission, silage $\mathrm{pH}$

\section{INTRODUÇÃO}

A aveia é muito utilizada para pastejo em sistema de integração lavoura pecuária no Sul do Brasil por apresentar boa produtividade e valor nutritivo. A ensilagem desta cultura surge do interesse em armazenar o excedente de forragem para substituir, ao menos parcialmente, a participação de silagens tradicionais como milho e sorgo, na busca pela produção mais econômica da pecuária.

A ensilagem em estádios de desenvolvimento que antecedem a formação de grãos é desejável, pois o valor nutritivo reduz com o avançar da maturidade (FONTANELLI et al., 2009). Nestes estádios, o teor de umidade é muito alto, seja pela elevada atividade em água, a qual favorece a proliferação de microrganismos indesejáveis, como os clostrídios, seja pela fermentação excessiva do material, pela ocorrência de proteólise e pela emissão de efluentes. Tavares et al. (2009) relataram que o uso de aditivos absorventes ou o emurchecimento da cultura tem sido a técnica mais recomendada para o controle da produção de efluentes em silagens.

A operação de pré-murchamento no campo é uma forma de minimizar os efeitos da umidade excessiva da forragem, pois eleva o teor de matéria seca, reduz a atividade da água, reduz ou cessa a emissão de efluente, e ainda pode elevar os teores de carboidratos solúveis na matéria verde e reduzir a capacidade tampão, conferindo melhores condições para fermentação lática e, por conseguinte, maior preservação do valor nutritivo da forragem.

Outra forma de melhorar a qualidade final da silagem é a redução no tamanho de partícula da forragem, pois embora limite a capacidade de produção do maquinário, aumenta a compactação e expulsão do ar no silo (NEUMANN et al., 2007); se a mesma for inferior a 20$30 \mathrm{~mm}$ pode, também, favorecer a disponibilidade de carboidratos solúveis, podendo promover redução na fermentação butírica e queda mais rápida do $\mathrm{pH}$ do material ensilado, além de menores perdas na desensilagem (SANTOS et al., 2010). No entanto, em materiais de elevada umidade, o aumento da densidade pode promover maiores perdas por emissão de efluentes (LOURES et al., 2003; PANZIANI, 2006a).

Este trabalho teve por objetivo avaliar o efeito do estádio fenológico, tamanho de partícula e o pré-murchamento sobre as características de fermentação e valor nutritivo da silagem de aveia preta (Avena strigosa Scherb).

\section{MATERIAL E MÉTODOS}

O experimento foi conduzido durante o período hibernal de 2011, no município de Renascença-PR, Brasil, em sucessão à cultura de sorgo safrinha para silagem. 
A área está localizada na região sudoeste do estado do Paraná, o solo é classificado como "latossolo vermelho" de textura argilosa (EMBRAPA, 2006). A análise de solo anterior ao experimento consta na Tabela 1 .

A semeadura de aveia preta, cultivar comum, foi realizada em 28 de maio de 2011, na densidade de $85 \mathrm{~kg} \mathrm{ha}^{-1}$, correspondendo a 373 plantas viáveis $\mathrm{m}^{-2}$, de acordo com teste de germinação (BRASIL, 2009), realizado no sistema de semeadura direta com espaçamento entre fileiras de $16 \mathrm{~cm}$. A adubação de base foi $16 \mathrm{~kg}$ de $\mathrm{N} \mathrm{ha}^{-1}, 40 \mathrm{~kg}$ de $\mathrm{P}_{2} \mathrm{O}_{5}$ $\mathrm{ha}^{-1}$ e $40 \mathrm{~kg}$ de $\mathrm{K}_{2} \mathrm{O} \mathrm{ha}^{-1}$ e também foi aplicada, em cobertura, uma dose de $40 \mathrm{~kg}$ de $\mathrm{N} \mathrm{ha}^{-1}$ na forma de ureia, no início do perfilhamento.

Tabela 1. Caracterização química do solo anteriormente à instalação do experimento

\begin{tabular}{lcccccccccc}
\hline Camada & $\mathrm{MO}$ & $\mathrm{P}$ & $\mathrm{K}$ & $\mathrm{pH}$ & $\mathrm{pH}$ & $\mathrm{Al}^{+3}$ & $\mathrm{H}+\mathrm{Al}$ & $\mathrm{Ca}$ & $\mathrm{Mg}$ & $\mathrm{CTC}$ \\
\hline $\mathrm{Cm}$ & $\mathrm{g} \mathrm{dm}^{-3}$ & $\mathrm{mg} \mathrm{dm}^{-3}$ & $\mathrm{CaCl}_{2}$ & $\mathrm{SMP}$ & \multicolumn{5}{c}{$\mathrm{cmol}_{\mathrm{c}} \mathrm{dm}^{-3}$} \\
\hline $0-20$ & 60,31 & 4,14 & 39,10 & 5,2 & 5,9 & 0,00 & 5,47 & 6,28 & 4,50 & 16,35 \\
\hline
\end{tabular}

Foi utilizado o delineamento inteiramente casualizado, em fatorial $(3 \times 2 \times 2)$ com quatro repetições, sendo os fatores tamanho de partícula (TP): 5; 13 , e $22 \mathrm{~mm}$, estádios de ensilagem: início do florescimento (IF) e florescimento pleno (FP), aos 98 e 113 dias após emergência, respectivamente, e operação de ensilagem: sem prémurchamento (SPM) e com prémurchamento (CPM).

O corte para ensilagem foi realizado com segadeira manual entre às 10:30 e 11:00 horas da manhã, com altura média de $18 \mathrm{~cm}$ acima da superfície do solo. O pré-murchamento foi realizado nos referidos tratamentos através da manutenção no campo durante 6 horas, com revolvimento da forragem a cada 2 horas. A fragmentação do material nos tamanhos definidos para cada tratamento foi realizada com colhedora de forragens modelo JF 9Z10. Posteriormente, o material foi ensilado em mini-silos de PVC de dimensões de $50 \mathrm{~cm}$ de altura e $10 \mathrm{~cm}$ de diâmetro, na densidade de $750 \mathrm{~kg} \mathrm{~m}^{-3}$. Os mini-silos possuíam um furo de $6 \mathrm{~mm}$ de diâmetro na parte basal, pelo qual se realizaram as coletas de efluentes, sendo as três primeiras coletas a cada três dias e as demais, semanalmente, até cessar emissão. O furo era mantido vedado com fita adesiva no período entre as coletas.

Aos cinco meses da ensilagem foram abertos os mini-silos, coletando amostras para procedimentos das análises laboratoriais. $\mathrm{O} \mathrm{pH}$, no momento da abertura do silo, foi medido conforme a metodologia de Silva \& Queiroz (2006). Parte da amostra foi congelada para posterior determinação da capacidade tampão (CT), segundo metodologia mencionada por Jobim et al. (2007). Outra parte foi seca em estufa de circulação forçada de ar a $65^{\circ} \mathrm{C}$ durante 72 horas para determinação do teor de matéria seca (MS), em seguida, moída em moinho tipo Wiley a $1 \mathrm{~mm}$ para avaliação bromatológica, sendo esta, corrigida para o teor de MS na temperatura de $105^{\circ} \mathrm{C}$ durante 24 horas. A matéria mineral $(\mathrm{MM})$ e proteína bruta (PB) foram determinadas segundo AOAC (2005), sendo a PB estimada, indiretamente, pelo método Kjeldahl. Os teores de fibra em detergente neutro 
(FDN) e fibra em detergente ácido (FDA) foram determinados por intermédio do equipamento ANKON, utilizando saquinhos confeccionados de tecido TNT - $100 \mathrm{~g} \mathrm{~m}^{-2}$, seguindo a metodologia de Van Soest (1991). A digestibilidade in vitro da matéria seca (DIVMS) foi executada segundo a metodologia de Tilley \& Terry (1963), com adaptação para a utilização do rúmen artificial, desenvolvida pela ANKON.

Os nutrientes digestíveis totais (NDT) foram estimados a partir da DIVMS, conforme Kunkle \& Bates (1998): MOD $=-0,664+[1,032$ (DIVMS) $]$, em que: $\mathrm{MOD}=$ Matéria orgânica digestível (\%); DIVMS = Digestibilidade in vitro da matéria seca $(\%)$. NDT $=$ MO $\{[26,8+0,595$ $(\mathrm{MOD})] / 100\}$, em que: NDT = Nutrientes digestíveis totais (\%) e MO = Matéria orgânica.

A determinação dessas características bromatológicas foi realizada no laboratório de Bromatologia da Universidade Tecnológica Federal do Paraná, campus Dois Vizinhos. Os dados foram submetidos à análise da variância pelo programa SAS versão 8.1 (SAS, 2001) e, quando significativos, comparados pelo teste de Tukey a 5\% de significância. Para o tamanho de partícula, quando observado diferença estatística pela análise de variância, foi realizado o teste de regressão. $\mathrm{O}$ valor do coeficiente de determinação foi calculado a partir da soma de quadrados da regressão considerada significativa, dividida pela soma de quadrados de tratamento.

\section{RESULTADOS E DISCUSSÃO}

Com relação ao teor de $\mathrm{MS}$ e $\mathrm{pH}$ da silagem, houve efeito de interação $(p<0,05)$ entre estádio $\mathrm{x}$ operação de pré-murchamento e estádio $\mathrm{x}$ tamanho de partícula (Tabela 2).

Segundo as equações de regressão, para o teor de MS em função da interação estádio de ensilagem e tamanho de partícula (Tabela 3), observa-se pequeno acréscimo linear para o estádio de IF e decréscimo para FP. O acréscimo no IF pode ser atribuído à redução da emissão de efluentes com o aumento do tamanho de partícula, corroborando com trabalho de Paziani et al. (2006a).

$\mathrm{O} \mathrm{pH}$ foi influenciado por todos os fatores e suas interações $(p<0,05)$ (Tabela 2). As equações de regressão para as interações do tamanho de partícula (Tabela 3) mostram decréscimo linear do $\mathrm{pH}$ com o aumento do tamanho de partícula, em todas as situações avaliadas de estádios de ensilagem e pré-murchamento, devido ao maior tamanho de partícula avaliado, neste trabalho, ser de apenas $2,2 \mathrm{~cm}$, sendo este, um tamanho adequado para compactação e processo fermentativo do material, permitindo a redução do $\mathrm{pH}$ a valores adequados para uma silagem de qualidade. Resultados distintos foram encontrados em silagem de capim Tanzânia (Panicum maximum, J. cv. Tanzânia), com pH de 4,99 para silagem com tamanho de partícula de $2,84 \mathrm{~cm}$ (LOURES et al., 2005) e 4,39 e 4,50 para menor e maior tamanho, obtido pela máxima variação da regulagem na colhedora de forragens, respectivamente (PANZIANI et al. 2006b). Estas variações no $\mathrm{pH} d a$ silagem não dependem somente do tamanho de partícula e da compactação, mas, também, do teor de matéria seca do material ensilado, que, quanto maior, menor deverá ser $\mathrm{o}$ tamanho da partícula. Sendo assim, os resultados observados são diversos, pois muitos são os fatores envolvidos na fermentação do material. 
Rev. Bras. Saúde Prod. Anim., Salvador, v.16, n.3, p.486-498 jul./set.., 2015 http://www.rbspa.ufba.br ISSN 15199940 http://dx.doi.org/10.1590/S1519-99402015000300002

Tabela 2. Quadro da análise de variância da composição bromatológica e características de fermentação de silagem de aveia preta, cultivar comum, submetida a diferentes tamanhos de partícula, estádio de ensilagem e pré-murchamento.

\begin{tabular}{|c|c|c|c|c|c|c|c|c|c|c|c|}
\hline \multirow[t]{2}{*}{ Fator } & \multirow[t]{2}{*}{ Gl } & \multicolumn{2}{|c|}{$\mathrm{MS}^{1}$} & \multicolumn{2}{|c|}{$\mathrm{pH}^{2}$} & \multicolumn{2}{|c|}{$\mathrm{CT}^{3}$} & \multicolumn{2}{|c|}{$\mathrm{FDN}^{4}$} & \multicolumn{2}{|c|}{$\mathrm{FDA}^{5}$} \\
\hline & & QM & $\mathrm{PR}>\mathrm{F}$ & QM & $\mathrm{PR}>\mathrm{F}$ & QM & $\mathrm{PR}>\mathrm{F}$ & QM & $\mathrm{PR}>\mathrm{F}$ & QM & $\mathrm{PR}>\mathrm{F}$ \\
\hline$E^{10}$ & 1 & 843,203 & 0,000 & 1,304 & 0,000 & 13354,67 & 0,000 & 2108,208 & 0,000 & 447,802 & 0,000 \\
\hline $\mathrm{O}^{11}$ & 1 & 1086,04 & 0,000 & 2,867 & 0,000 & 14267,82 & 0,000 & 96,248 & 0,000 & 61,903 & 0,000 \\
\hline $\mathrm{TP}^{12}$ & 2 & 0,239 & 0,789 & 0,432 & 0,002 & 59,126 & 0,300 & 5,944 & 0,093 & 2,013 & 0,252 \\
\hline $\mathrm{E}^{*} \mathrm{O}$ & 1 & 90,956 & 0,000 & 0,619 & 0,003 & 18,106 & 0,541 & 2,935 & 0,270 & 0,803 & 0,454 \\
\hline $\mathrm{E}^{*} \mathrm{TP}$ & 2 & 7,618 & 0,002 & 0,715 & 0,000 & 290,844 & 0,005 & 0,617 & 0,770 & 0,244 & 0,841 \\
\hline O*TP & 2 & 0,533 & 0,591 & 0,310 & 0,010 & 35,492 & 0,480 & 2,191 & 0,401 & 2,245 & 0,216 \\
\hline $\mathrm{E}^{*} \mathrm{O} * \mathrm{TP}$ & 2 & 0,222 & 0,802 & 0,712 & 0,000 & 135,426 & 0,071 & 6,719 & 0,070 & 3,721 & 0,084 \\
\hline Media & - & 25,241 & - & 3,396 & - & 70,439 & - & 62,427 & - & 40,266 & - \\
\hline $\mathrm{CV}$ & - & 4,289 & - & 7,149 & - & 9,777 & - & 2,450 & - & 2,942 & - \\
\hline
\end{tabular}

\begin{tabular}{lccccccccccc}
\hline & GL & QM & PR $>$ F & QM & PR $>$ F & QM & PR $>$ F & QM & PR $>F$ & \\
\hline E & 1 & 487,050 & 0,000 & 42,150 & 0,000 & 1363,094 & 0,000 & 296,510 & 0,000 & - & - \\
O & 1 & 47,203 & 0,000 & 0,013 & 0,306 & 193,965 & 0,000 & 59,809 & 0,000 & - & - \\
TP & 2 & 0,069 & 0,910 & 0,008 & 0,516 & 8,407 & 0,160 & 2,426 & 0,175 & - & - \\
E*O & 1 & 2,367 & 0,080 & 0,002 & 0,681 & 0,698 & 0,691 & 0,168 & 0,724 & - & - \\
E*TP & 2 & 0,086 & 0,889 & 0,034 & 0,079 & 1,952 & 0,642 & 0,578 & 0,650 & - & - \\
O*TP & 2 & 0,508 & 0,505 & 0,014 & 0,344 & 0,497 & 0,892 & 0,126 & 0,910 & - & - \\
E*O*TP & 2 & 0,532 & 0,490 & 0,003 & 0,784 & 11,305 & 0,088 & 3,529 & 0,084 & - & - \\
\hline Media & - & 15,369 & - & 7,362 & - & 36,149 & - & 44,723 & - & - \\
\hline CV & - & 5,562 & - & 1,512 & - & 5,772 & - & 2,575 & - & - \\
\hline
\end{tabular}

${ }^{1}$ Matéria seca da silagem, ${ }^{2}$ potencial de hidrogênio, ${ }^{3}$ capacidade tampão (meq de $\mathrm{NaOH}(0,1 \mathrm{~N})$ para elevar o $\mathrm{pH}$ de 4,0 para 6,0 100 $\mathrm{g} \mathrm{MS}^{-1}$ ), ${ }^{4}$ fibra em detergente neutro, ${ }^{5}$ fibra em detergente ácido, ${ }^{6}$ proteína bruta, ${ }^{7}$ matéria mineral, ${ }^{8}$ digestibilidade in vitro da matéria seca, ${ }^{9}$ nutrientes digestíveis totais, ${ }^{10}$ estádio, ${ }^{11}$ operação, ${ }^{12}$ tamanho de partícula. 
Rev. Bras. Saúde Prod. Anim., Salvador, v.16, n.3, p.486-498 jul./set.., 2015 http://www.rbspa.ufba.br

Tabela 3. Equações de regressão e coeficientes de determinação $\left(r^{2}\right)$ para composição bromatológica e características de fermentação referente ao fator tamanho de partícula e respectivas interações para silagem de aveia preta (Avena strigosa S.), cultivar comum

\begin{tabular}{|c|c|c|c|}
\hline Variáveis & Níveis & Equação de regressão & $r^{2}$ \\
\hline \multirow{2}{*}{$\mathrm{MS}^{1}$} & $\mathrm{IF}^{10}$ & $19,602+0,0826 X$ & 0,99 \\
\hline & $\mathrm{FP}^{11}$ & $31,007-0,0922 \mathrm{X}$ & 0,88 \\
\hline \multirow{4}{*}{$\mathrm{pH}^{2}$} & IF & $3,291-0,0045 X$ & 0,25 \\
\hline & FP & $3,770-0,0157 X$ & 0,15 \\
\hline & $\mathrm{SPM}^{12}$ & $3,739-0,0074 X$ & 0,05 \\
\hline & $\mathrm{CPM}^{13}$ & $3,322-0,0128 X$ & 0,99 \\
\hline \multirow{2}{*}{$\mathrm{CT}^{3}$} & IF & $94,929-0,5858$ X & 0,89 \\
\hline & FP & $50,615+0,2358 X$ & 0,23 \\
\hline $\mathrm{FDN}^{4}$ & - & 62,42 & - \\
\hline $\mathrm{FDA}^{5}$ & - & 40,26 & - \\
\hline $\mathrm{PB}^{6}$ & - & 15,37 & - \\
\hline $\mathrm{MM}^{7}$ & - & 7,36 & - \\
\hline DIVMS $^{8}$ & - & 36,15 & - \\
\hline $\mathrm{NDT}^{9}$ & - & 44,72 & - \\
\hline
\end{tabular}

Nos trabalhos mencionados acima, foram utilizadas colhedoras de forragens de duplo corte, as quais realizam o ajuste de tamanho de partícula pelo distanciamento da contrafaca em relação à faca, apresentando grande variação no tamanho de partícula, a qual apresentou pouca sensibilidade para caracterizar diferenças na dimensão das mesmas (PANZIANI et al., 2006b). Os autores atribuem este efeito à melhor compactação devido ao menor tamanho de partícula, que alterou a densidade da silagem. A melhor compactação promove a expulsão do ar, permitindo que a fase aeróbica no processo de fermentação seja reduzida (AMARAL et al., 2007).

Por outro lado, no presente estudo o efeito da compactação foi isolado, utilizando o mesmo peso de massa verde para todos os tratamentos, com isso, supostamente, não houve efeito de compactação no $\mathrm{pH}$ da silagem. Também não é possível afirmar a tendência de redução no pH pela variação numérica de baixa magnitude e pelos coeficientes de determinação ajustados serem pouco expressivos. Neumann et al. (2005), ensilando sorgo, não encontraram efeito do tamanho de 
partícula sob o $\mathrm{pH}$ da silagem. O efeito de interação entre estádio $\mathrm{x}$ operação (Tabela 4) mostra menores valores para o CPM, o qual está associado à menor CT, nesta operação (Tabela 4), corroborando com trabalho de Berto \& Mühlbach (1997).

De acordo com o efeito de interação entre estádio e operação (Tabela 4), verifica-se elevação do teor de MS em ambos os estádios com murchamento, atribuído ao efeito de perda de umidade no campo (BERTO \& MÜHLBACH, 1997). A elevação no teor de MS, na ordem de $42,96 \%$ e $57,39 \%$ para IF e
FP, respectivamente, pode representar uma melhora na qualidade fermentativa da silagem, sobretudo para o IF, em que os teores são menores em função do grande volume de água presente na forragem. A ensilagem deve ser realizada com teor de MS entre 28 a $35 \%$ para que haja boa qualidade na fermentação. No entanto, silagens acima de $20 \%$ podem ser de boa qualidade, desde que contenham um adequado nível de substratos fermentáveis na forma de carboidratos solúveis e baixa capacidade tampão (McDONALD et al., 1991).

Tabela 4. Efeito de interação estádio operação para teor de MS e pH de silagem de aveia preta, cultivar comum, submetida a diferentes tamanhos de partícula, estádio de ensilagem e pré-murchamento*

\begin{tabular}{lccccc}
\hline Variável & \multicolumn{3}{c}{$\mathrm{MS}^{1}$} & \multicolumn{2}{c}{$\mathrm{pH}^{2}$} \\
\hline Estádio & & $\mathrm{IF}^{3}$ & $\mathrm{FP}^{4}$ & $\mathrm{IF}$ & $\mathrm{FP}$ \\
\hline \multirow{2}{*}{ Operação } & $17,04^{\mathrm{Bb}}$ & $23,14^{\mathrm{Ab}}$ & $3,36^{\mathrm{Ba}}$ & $3,92^{\mathrm{Aa}}$ \\
& $\mathrm{SPM}^{5}$ & $24,36^{\mathrm{Ba}}$ & $36,42^{\mathrm{Aa}}$ & $3,10^{\mathrm{Bb}}$ & $3,20^{\mathrm{Ab}}$ \\
\hline
\end{tabular}

${ }^{1}$ Matéria seca $(\%),{ }^{2}$ Potencial de hidrogênio, ${ }^{3}$ Início do florescimento, ${ }^{4}$ Florescimento pleno, ${ }^{5}$ Sem prémurchamento, ${ }^{6}$ Com pré-murchamento.

*Médias seguidas de letras minúsculas, distintas na coluna, e maiúsculas, na linha, diferem entre si pelo teste de Duncan, ao nível de 5\% de significância.

A capacidade tampão sofreu efeito $(p<0,05)$ de interação entre tamanho de partícula $\mathrm{x}$ estádio de ensilagem, bem como foi influenciada isoladamente pelo fator operação de prémurchamento (Tabela 2). A capacidade tampão foi reduzida em $39,32 \%$, de 87,68 para 53,20 meq $\mathrm{NaOH} 100 \mathrm{~g} \mathrm{MS}^{-}$ 1, pela operação COM (Tabela 5), corroborando com trabalhos de Berto \& Mühlbach (1997) em aveia preta, cujos dados mostraram que $o$ prémurchamento de 15,3 para $31,2 \%$ de MS reduziu a CT em 14,6\%. Evangelista et al. (2004), em capimmarandu (Brachiaria brizantha S. cv.
Marandu), verificaram diminuição de aproximadamente 1,59 meq $\mathrm{HCl} 100 \mathrm{~g}$ $\mathrm{MS}^{-1}$ para o acréscimo de cada uma hora de secagem.

O pré-murchamento limita o desenvolvimento das bactérias do gênero Clostridium, o qual, normalmente, é inibido acima de $30 \%$ de MS, deste modo, são reduzidas as perdas por fermentações secundárias indesejáveis, principalmente pela fermentação de açúcares, ácidos orgânicos e proteínas, disponibilizando, assim, menos íons inorgânicos para formação do sistema tampão com os ácidos orgânicos, produzidos durante $\mathrm{o}$ processo 
(McDONALD et al., 1991). A interação entre tamanho de partícula e estádio de ensilagem (Tabela 3) mostra redução linear na capacidade tampão no estádio de IF; em contrapartida, é elevada linearmente no FP. Este efeito está condicionado à relação inversa ao teor de MS, como descrito acima.

O estádio influenciou a CT $(\mathrm{p}<0,05)$, apresentando redução de $38,30 \%$ no florescimento pleno, quando comparado com início de florescimento (Tabela 5), o que pode ser explicado pela redução dos teores de ácidos orgânicos com a maturidade da planta e uma possível redução nas bases inorgânicas (potássio e cálcio), uma vez que reduziu também os teores de MM. Floss et al. (2003) também encontraram redução linear nos teores de cálcio e potássio com a maturidade de aveia branca.

Tabela 5. Composição bromatológica e características de fermentação referente aos fatores estádio e operação, sem efeito de interação para silagem de aveia preta, cultivar comum

\begin{tabular}{lllllllll}
\hline Fator & & $\mathrm{CT}^{1}$ & $\mathrm{FDN}^{2}$ & $\mathrm{FDA}^{3}$ & $\mathrm{~PB}^{4}$ & $\mathrm{MM}^{5}$ & DIVMS $^{6}$ & $\mathrm{NDT}^{7}$ \\
\hline \multirow{2}{*}{ Estádio } & $\mathrm{IF}^{8}$ & $87,12^{\mathrm{a}}$ & $55,80^{\mathrm{b}}$ & $37,21^{\mathrm{b}}$ & $18,55^{\mathrm{a}}$ & $8,30^{\mathrm{a}}$ & $41,48^{\mathrm{a}}$ & $47,21^{\mathrm{a}}$ \\
& $\mathrm{FP}^{9}$ & $53,76^{\mathrm{b}}$ & $69,05^{\mathrm{a}}$ & $43,32^{\mathrm{a}}$ & $12,18^{\mathrm{b}}$ & $6,43^{\mathrm{b}}$ & $30,82^{\mathrm{b}}$ & $42,24^{\mathrm{b}}$ \\
\hline \multirow{2}{*}{ Operação } & $\mathrm{SPM}^{10}$ & $87,68^{\mathrm{a}}$ & $63,84^{\mathrm{a}}$ & $41,40^{\mathrm{a}}$ & $14,38^{\mathrm{b}}$ & $7,38^{\mathrm{ns}}$ & $34,14^{\mathrm{b}}$ & $43,61^{\mathrm{b}}$ \\
& $\mathrm{CPM}^{11}$ & $53,20^{\mathrm{b}}$ & $61,01^{\mathrm{b}}$ & $39,13^{\mathrm{b}}$ & $16,36^{\mathrm{a}}$ & 7,35 & $38,16^{\mathrm{a}}$ & $45,84^{\mathrm{a}}$
\end{tabular}

${ }^{1}$ Capacidade tampão (meq de $\mathrm{NaOH}(0,1 \mathrm{~N})$ para elevar o $\mathrm{pH}$ de 4,0 para $\left.6,0100 \mathrm{~g} \mathrm{MS}^{-1}\right),{ }^{2}$ fibra em detergente neutro (\%), ${ }^{3}$ fibra em detergente ácido (\%), ${ }^{4}$ proteína bruta (\%), ${ }^{5}$ matéria mineral (\%), ${ }^{6}$ digestibilidade in vitro da matéria seca (\%), ${ }^{7}$ nutrientes digestíveis totais (\%), ${ }^{8}$ início do florescimento, ${ }^{9}$ florescimento pleno, ${ }^{10}$ sem pré-murchamento, ${ }^{11}$ com pré-murchamento.

*Médias seguidas de letras distintas na coluna para cada fator diferem entre si pelo teste de Duncan, ao nível de 5\% de significância. "ns": não significativo.

Os valores observados para CT, principalmente com relação às médias dos tratamentos IF e SPM, sendo superiores a $87 \mathrm{meq} \mathrm{NaOH} 100 \mathrm{~g} \mathrm{MS}^{-1}$, estão acima dos encontrados por Meinerz et al. (2011) para aveia branca UPF 18, no estádio de grão pastoso, de $14,72 \mathrm{meq} \quad \mathrm{NaOH} \quad 100 \mathrm{~g} \mathrm{MS}^{-1}$, e próximos ao de triticale (Secale cereale L.) em grão farináceo, de 71,93 meq $\mathrm{NaOH} \quad 100 \mathrm{~g} \mathrm{MS}^{-1}$ (BUMBIERIS JUNIOR et al., 2010).

Os valores mais elevados para CT estão relacionados aos ácidos formados pela fermentação, que tendem a aumentar a capacidade tampão quando o material ensilado estabiliza. Fato este, visualizado por Pinto et al. (2012), trabalhando com silagem de bagaço de laranja, na qual a produção de ácido lático ocorreu até 70 dias de ensilagem, porém a redução no $\mathrm{pH}$ ocorreu somente até 40 dias de ensilagem, e os ácidos produzidos elevaram a $\mathrm{CT}$, que apresentou aumento linear em relação ao tempo de abertura dos silos.

As frações fibrosas de FDN e FDA foram afetadas $(p<0,05)$ somente pelos fatores estádio e operação de prémurchamento, sem efeito de interação (Tabela 2). Os teores se elevaram, com a maturidade da planta, de 55,80 para $69,05 \%$ para FDN, e de 37,21 para $43,32 \%$ para FDA, nos tratamentos IF e 
FP, respectivamente. Os teores de FDN e FDA obtidos neste trabalho são próximos aos encontrados por Floss et al. (2003), no momento da ensilagem, o que é atribuído ao avanço da maturidade da aveia.

A operação de pré-murchamento reduziu significativamente $(\mathrm{p}<0,05)$ os teores de FDN e FDA (Tabela 4). Esta redução pode ser atribuída à perda de efluentes no tratamento sem murchamento (Tabela 6), carreando substâncias solúveis em quantidade suficiente para elevar a proporção das frações fibrosas. $\mathrm{O}$ efeito do prémurchamento proporcionou melhores condições para fermentação e estabilidade do ensilado, com menores perdas do valor nutritivo, enquanto para o SPM, a ocorrência de fermentações secundárias indesejáveis, degradação de proteínas e outros compostos, os quais elevaram a CT (Tabela 2), possivelmente foram responsáveis por elevar a proporção das frações fibrosas FDN e FDA. Foi utilizado, para ambos os tratamentos, a densidade de $750 \mathrm{~kg}$ $\mathrm{m}^{3}$ na matéria original, para a operação SPM, com maior umidade, o que, possivelmente, manteve maior presença de oxigênio; com isso, a fase aeróbica de fermentação pode ter sido mais acentuada, prejudicando, ainda mais, o processo fermentativo.

A PB foi influenciada $(p<0,05)$ também, de maneira isolada, pelos fatores estádio e operação, sem haver interação (Tabela 2). Houve redução de $34,3 \%$ (18,55 vs. $12,18 \%$ ) na $\mathrm{PB}$ do estádio FP, em relação ao IF (Tabela 5), em decorrência da maturidade da planta. A operação de pré-murchamento foi responsável por preservar melhor as características da forragem, uma vez que, o tratamento SPM apresentou perdas de $12,10 \%$ na $\mathrm{PB}$, quando comparado ao CPM (14,38 vs. $16,36 \%$, respectivamente). Isso demonstra a ocorrência de proteólise, com degradação excessiva da PB. Corroborando com isso, Berto \& Mühlbach (1997) encontraram redução de $22 \%$ no teor de $\mathrm{PB}$, o que foi associado à lixiviação do $\mathrm{N}$ na massa ensilada por emissão de efluentes.

A fração de $M M$ foi afetada $(\mathrm{p}<0,05)$ apenas pelo fator estádio (Tabela 2), com redução no teor de 8,30 para $6,43 \%$ nos tratamentos IF e FP, respectivamente (Tabela 5). A redução foi em decorrência do desenvolvimento fisiológico da planta, com perda ou diluição dos nutrientes na massa total de forragem, e com o avanço da maturidade, conforme também relatado por Floss et al. (2007).

A DIVMS foi alterada significativamente $\quad(p<0,05)$ apenas pelos fatores estádio e operação de prémurchamento, sem efeito de interação (Tabela 2). Houve redução de $25,7 \%$ na DIVMS $(41,48$ vs. $30,82 \%)$ para o estádio de IF com relação ao $\mathrm{FP}$, respectivamente (Tabela 5). Esta redução está associada à elevação dos teores de compostos estruturais, tais como a celulose, hemicelulose e a lignina, que constituem a FDN. Floss et al. (2003) visualizaram redução com o avanço da maturidade da planta, cuja equação estimaria valores de 53,05 e $45,72 \%$ para o estádio de início do florescimento e florescimento pleno, respectivamente, para aveia branca no momento da ensilagem. A operação de pré-murchamento elevou em 11,77\% a DIVMS (34,14 vs. 38,16\%) para o SPM comparado com o CPM, sendo, este efeito, atribuído às menores frações de FDN e FDA e maior teor de PB para este tratamento.

O NDT seguiu a mesma tendência da DIVMS, sendo influenciado apenas pelos fatores estádio e operação isoladamente (Tabela 2) e apresentando redução, com o avanço da maturidade, 
de 47,21 para 42,24\% no estádio de IF e FP, respectivamente, sendo que, o prémurchamento elevou o NDT de 43,6 para $45,84 \%$, quando comparado ao sem pré-murchamento (Tabela 5). A elevação no NDT com o avanço do ciclo da cultura é esperada, uma vez que há maior acúmulo de materiais fibrosos (FDN e FDA) e redução nos teores de nutrientes na forragem com a maturidade da cultura e menor parede celular presente no tratamento CPM, que promove aumento significativo no teor de NDT.

A produção de efluentes ocorreu apenas no estádio de IF e sem a operação de prémurchamento (Tabela 6), não sendo detectada nos demais tratamentos avaliados. O teor de MS médio da silagem, neste tratamento, foi de $17,04 \%$, e a produção média de efluentes foi de $80,98 \mathrm{~L} \mathrm{t}^{-1}$, sem diferença significativa entre os tamanhos de partícula.

Tabela 6. Produção de efluentes na ensilagem de aveia preta, cultivar comum, no estádio de início do florescimento sem pré-murchamento

\begin{tabular}{lccccc}
\hline \multirow{2}{*}{ Variável } & \multicolumn{3}{c}{ Tamanho de partícula $(\mathrm{mm})$} & \multirow{2}{*}{ Média } & CV (\%) \\
\cline { 2 - 4 } & 5 & 13 & 22 & & \\
\hline MS (\%) & $16,49^{\mathrm{ns}}$ & 17,07 & 17,58 & 17,04 & 4,6 \\
Efluente $\left(\mathrm{L} \mathrm{t}^{-1}\right)$ & $72,07^{\mathrm{ns}}$ & 95,17 & 75,69 & 80,98 & 19,8 \\
\hline
\end{tabular}

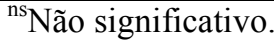

As perdas por efluente reduzem o valor nutricional da silagem, pois, na solução, existem nutrientes, como carboidratos solúveis, ácidos orgânicos, minerais e compostos nitrogenados solúveis, o que leva à maior proporção dos componentes da parede celular na silagem, que são, nutricionalmente, menos desejáveis (FARIA et al. 2010). Essas perdas de efluentes desencadeiam em uma elevada demanda bioquímica de oxigênio, o qual demanda silos revestidos para coleta, produz odor desagradável e pode contribuir na proliferação de insetos, o que não é desejável nas proximidades, principalmente, de instalações de produção leiteira. Com isso, pode-se afirmar que o pré-murchamento foi efetivo na inibição da emissão de efluentes, quando a silagem é confeccionada no IF, ao passo que, no estádio de florescimento pleno, não há necessidade de pré-murchamento, pois não há emissão de efluentes.

Assim, constatou-se que o tamanho de partícula tem efeito significativo apenas no $\mathrm{pH}$ da forragem de aveia preta ensilada, sem efeitos na qualidade bromatológica da silagem produzida.

A operação de pré-murchamento é eficiente em restringir a produção de efluentes no início do florescimento. Também confere, à silagem, melhores condições de fermentação, com menor $\mathrm{CT}$ e, consequentemente, menor $\mathrm{pH}$.

Com base no valor nutricional, a ensilagem no estádio de início do florescimento com pré-murchamento apresenta maiores teores de PB, DIVMS e NDT, ao passo que apresenta menores teores de FDN e FDA. 
Rev. Bras. Saúde Prod. Anim., Salvador, v.16, n.3, p.486-498 jul./set.., 2015 http://www.rbspa.ufba.br

\section{REFERÊNCIAS}

AMARAL, R.C.; BERNARDES, T.F.B.; SIQUEIRA, G.R.; REIS, R.A.

Características fermentativas e químicas de silagens de capim-marandu produzidas com quatro pressões de compactação.

Revista Brasileira de Zootecnia, v.36, n.3, p.532-539, 2007.

\section{ASSOCATION OF OFFICIAL}

ANALYTICAL CHEMISTRY - AOAC. Official methods of analysis. 18.ed. Arlington, 2005. 1117p.

BERTO, J.L.; MÜHLBACH, P.R.F. Silagem de aveia preta no estádio vegetativo, submetida à ação de inoculantes e ao efeito do emurchecimento. Revista Brasileira de Zootecnia, v. 26, p. 651-658, 1997.

BRASIL. Ministério da Agricultura, Pecuária e Abastecimento. Regras para análise de sementes. Brasília: Mapa/ACS, 2009. 399 p.

BUMBIERIS JUNIOR,V.H.; JOBIM, C.C.; EMILE, J.C.; ROMAN, J.; SILVA, M.S. Aerobic stability of triticale silage in single culture or in mixtures with oat and/or legumes. Revista Brasileira de Zootecnia, v. 39, p. 2349-2356, 2010.

EMPRESA BRASILEIRA DE PESQUISA AGROPECUÁRIA EMBRAPA. Sistema brasileiro de classificação de solos. 2 . ed. Rio de Janeiro: Embrapa Solos, 306p. 2006.

EVANGELISTA, A.R.; ABREU, J.G.; AMARAL, P.N.C.; PEREIRA, R.C.; SALVADOR, F.M.; SANTANA, R.A.V. Produção de silagem de Capim-marandu (Brachiaria brizantha Stapf cv.

Marandu) com e sem emurchecimento. Ciência e Agrotecnologia, v.28, p. 443449, 2004.
FARIA, D.J.L.; GARCIA, R.; TONUCCI, R.G.; TAVARES, V.B.; PEREIRA, O.G.; FONSECA, D.M. Produção e composição do efluente da silagem de capim-elefante com casca de café. Revista Brasileira de Zootecnia, v.39, n.3, p.471-478, 2010.

FONTANELI, R.S.; FONTANELI, R.S.; SANTOS, H.P. NASCIMENTO JUNIOR, A.; MINELLA, E.; CAIERÃO, E. Rendimento e valor nutritivo de cereais de inverno duplo propósito: forragem verde e silagem ou grãos. Revista Brasileira de

Zootecnia, v.38, n.11, p.2116-2120, 2009.

FLOSS, E.L.; BOIN, C.; PALHANO, A.L.; SOARES FILHO, C.V.; PREMAZZI, L.M. Efeito do estádio de maturação sobre o rendimento e valor nutritivo da aveia branca no momento da ensilagem. Boletim de Indústria Animal, v.60, p.117-126, 2003.

FLOSS, E.L.; PALHANO, A.L.; SOARES FILHO, C.V.; PREMAZZI, L.M. Crescimento, produtividade, caracterização e composição química da aveia branca. Acta Scientiarum: Animal Science, v.29, p.1-7, 2007.

JOBIM, C.C.; NUSSIO, L.G.; REIS, R.A.; SCHMIDT, P. Avanços metodológicos na avaliação da qualidade da forragem conservada. Revista Brasileira de Zootecnia, v.36, p.101-119, 2007. Supl.

KUNKLE, W.E.; BATES, D.B. Evaluating feed purchasing options: energy, protein, and mineral supplements. In: FLORIDA BEEF CATTLE SHORT COURSE, 1998, Gainesville. Proceedings... Gainesville: University of Florida, 1998. p.59-70. 
Rev. Bras. Saúde Prod. Anim., Salvador, v.16, n.3, p.486-498 jul./set.., 2015 http://www.rbspa.ufba.br ISSN 15199940

LOURES, D.R.S.; GARCIA, R.; PEREIRA, O.G.; CECON, P.R.; SOUZA, A.L. Características do efluente e composição químicobromatológica da silagem de capimelefante sob diferentes níveis de compactação. Revista Brasileira de Zootecnia, v.32, p.1851-1858, 2003.

LOURES, D.R.S.; NUSSIO, L.G.; PAZIANI, S.F.; PEDROSO, A.F.; MARI, L. J.; RIBEIRO, J.L.; ZOPOLLATTO, M.; SCHMIDT, P.; JUNQUEIRA, M.C.; PACKER, I.U., CAMPOS, F.P. Composição

Bromatológica e Produção de Efluente de Silagens de Capim-Tanzânia sob Efeitos do Emurchecimento, do Tamanho de Partícula e do Uso de Aditivos Biológicos. Revista Brasileira de Zootecnia, v.34, p.726-735, 2005.

McDONALD, P.; HENDERSON, A.R.; HERON, S.J.E. The biochemistry of silage. 2.ed. Marlow: Chalcomb Publications, 1991. 340p.

MEINERZ, G.R.; OLIVO, C.J.; VIÉGAS, J.; NÖRNBERG, J.L.; AGNOLIN, C.A.; SCHEIBLER, R.B.; HORST, T.; FONTANELI, R.S. Silagem de cereais de inverno submetidos ao manejo de duplo propósito. Revista Brasileira de Zootecnia, v.40, p.2097-2104, 2011.

NEUMANN, M.; RESTLE, J.; BRONDANI, I.L.; NÖRNBERG, J.L.; MELLO, R.O.; SOUZA, A.N.M.; PELLEGRINI, L.G. Efeito do tamanho de partícula e do tipo de silo sobre o valor nutritivo da silagem de sorgo (Sorghum bicolor, L. Moench). Revista Brasileira do Milho e Sorgo, v.4, p.224-242, 2005.
NEUMANN, M.; MÜHLBACH, P.R.F.; NÖRNBERG, J.L.; RESTLE, J.; OST, P.R. Ensilagem de milho (Zea mays, $L$.) em diferentes alturas de corte e tamanho de partícula: produção, composição e utilização na terminação de bovinos em confinamento. Revista Brasileira do Milho e Sorgo, v.6, p.379-397, 2007.

PAZIANI, S.de F.; NUSSIO, L.G.; LOURES, D.R.S.; IGARASI, M.S.; PEDROSO, A.de F.; MARI, L.J. Influência do teor de matéria seca e do inoculante bacteriano nas características físicas e químicas da silagem de capim Tanzânia. Acta Scientiarum: Animal Sciences, v.28, n.3, p.265-271, 2006a.

PAZIANI, S.F.; NUSSIO, L.G.; PIRES, A.V.; RIBEIRO, J.L.; ZOPOLLATTO, M.; SCHMIDT, P. Efeito do emurchecimento e do inoculante bacteriano sobre a qualidade da silagem de capim Tanzânia e o desempenho de novilhas. Acta Scientiarum: Animal Science, v.28, p.393-400, 2006b.

PINTO, A.P.; MIZUBUTI, I.Y.; RIBEIRO, E.L.A.; PEREIRA, E.S.; BUMBIERIS JUNIOR, V.H.; PIMENTEL, P.G.; SALMAZO, R.; CARNEIRO, M.S.S. Avaliações das silagens de bagaço de laranja e de milho com diferentes aditivos protéicos.

Semina: Ciências Agrárias, v.33, p.3305-3314, 2012.

SANTOS, M.V.F.; CASTRO, A.G.G.; PEREA, J.M.; GARCÍA, A.; GUIM, A.; HERNÁNDEZ, M. P. Fatores que afetam o valor nutritivo da silagens de forrageiras tropicais. Archivos de Zootecnia, v.59, p.25-43, 2010.

STATISTICAL ANALYSIS SYSTEM SAS. SAS user's guide: statistics. Version 8.1. Cary, 2001. 
Rev. Bras. Saúde Prod. Anim., Salvador, v.16, n.3, p.486-498 jul./set.., 2015 http://www.rbspa.ufba.br

SILVA, D.J.; QUEIROZ, A.C. Análise de alimentos: métodos químicos e biológicos. 3. ed. Viçosa, MG:

Universidade Federal de Viçosa, 2006.

TAVARES, V.B.; PINTO, J.C.;

EVANGELISTA, A.R.; FIGUEIREDO, H.C.P.; ÁVILA, C.L.S.; LIMA, R.F.

Efeitos da compactação, da inclusão de aditivo absorvente e do emurchecimento na composição bromatológica de silagens de capimtanzânia. Revista Brasileira de

Zootecnia, v.38, p.40-49, 2009.

TILLEY, J.M.A.; TERRY, R.A. A twostage technique for the in vitro digestion of forage crops. Grass and Forage

Science, v.18, p.104-111, 1963.

VAN SOEST, P.J.; ROBERTSON, J.B.; LEWIS, B.A. Methods for dietary fiber, and nonstarch polysaccharides in relation to animal nutrition. Journal of Dairy Science, v.74, n.10, p.3583-3597, 1991.

Data de recebimento: $16 / 07 / 2014$

Data de aprovação: 13/08/2015 